\title{
Suggestion for a subdivision of processed meat products on the Danish market based on their content of carcinogenic compounds
}

Mejborn, Heddie; Hansen, Max; Biltoft-Jensen, Anja Pia; Christensen, Tue; Ygil, Karin Hess; Olesen, Pelle Thonning

\section{Published in:}

Meat Science

Link to article, DOI:

10.1016/j.meatsci.2018.08.025

Publication date:

2019

Document Version

Peer reviewed version

Link back to DTU Orbit

Citation (APA):

Mejborn, H., Hansen, M., Biltoft-Jensen, A. P., Christensen, T., Ygil, K. H., \& Olesen, P. T. (2019). Suggestion for a subdivision of processed meat products on the Danish market based on their content of carcinogenic compounds. Meat Science, 147, 91-99. https://doi.org/10.1016/j.meatsci.2018.08.025

\section{General rights}

Copyright and moral rights for the publications made accessible in the public portal are retained by the authors and/or other copyright owners and it is a condition of accessing publications that users recognise and abide by the legal requirements associated with these rights.

- Users may download and print one copy of any publication from the public portal for the purpose of private study or research.

- You may not further distribute the material or use it for any profit-making activity or commercial gain

- You may freely distribute the URL identifying the publication in the public portal 


\section{Accepted Manuscript}

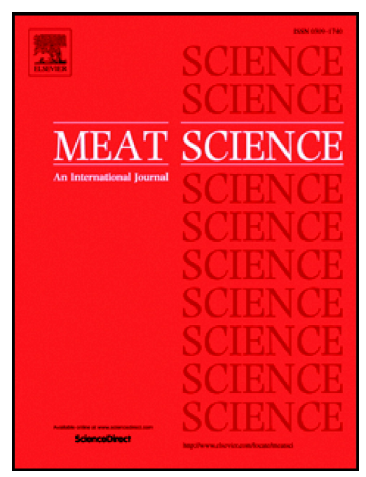

Heddie Mejborn, Max Hansen, Anja Biltoft-Jensen, Tue Christensen, Karin Hess Ygil, Pelle Thonning Olesen

PII:

S0309-1740(18)30163-3

DOI: doi:10.1016/j.meatsci.2018.08.025

Reference:

MESC 7674

To appear in:

Meat Science

Received date:

19 February 2018

Revised date:

12 July 2018

Accepted date:

29 August 2018

Please cite this article as: Heddie Mejborn, Max Hansen, Anja Biltoft-Jensen, Tue Christensen, Karin Hess Ygil, Pelle Thonning Olesen, Suggestion for a subdivision of processed meat products on the Danish market based on their content of carcinogenic compounds. Mesc (2018), doi:10.1016/j.meatsci.2018.08.025

This is a PDF file of an unedited manuscript that has been accepted for publication. As a service to our customers we are providing this early version of the manuscript. The manuscript will undergo copyediting, typesetting, and review of the resulting proof before it is published in its final form. Please note that during the production process errors may be discovered which could affect the content, and all legal disclaimers that apply to the journal pertain. 


\section{Suggestion for a subdivision of processed meat products on the Danish market based on their content of carcinogenic compounds}

Heddie Mejborn ${ }^{1}$, Max Hansen, Anja Biltoft-Jensen, Tue Christensen, Karin Hess Ygil, Pelle Thonning Olesen National Food Institute, Technical University of Denmark, Kgs. Lyngby, Denmark

\section{Abstract}

Carcinogenic effects in humans are ascribed to processed meat by organisations such as International Agency for Research on Cancer, World Cancer Research Fund and American Institute for Cancer Research. However, the term 'processed meat' covers a heterogenicgroup of products whose content of pot ential hazards differ considerably. To improve estimates of associations betw een processed meat intake and cancer risk we investigated ways to divide processed meat into subgroups that more precisely reflects its carcinogenic characteristics.

We collected ingredient lists and declarations of salt content for more than 1000 processed meat products on the Danish market and combined the information with knowledge related to processing parameters. Some compounds that could affect the products' carcinogenic characteristics, alone or in combination, were evaluated and compared for 12 types of processed meat products, and we suggest subgrouping of processed meat with similar level of carcinogenic potential, which could improve the understanding of the cancer risk associated with processed meat intake in scientific human studies.

\section{Keywords}

Cancer, haem iron, nitrite/nitrate/N-nitroso compounds, PAH, HCA, epidemiology

1. Introduction

Several cancers are multifactorial, among others affected by lifestyle and diet. The International Agency for Research on Cancer (IARC) has evaluated processed meat's possible carcinogenic effect (IARC, 2018). IARC concluded that processed meat should be classified as 'carcinogenic to hu mans (Group 1)' based on "sufficient evidence" in humans for the carcinogenicity of consumption of processed meat and "moderate" mechanistic evidence. Likewise the World Cancer Research Fund and American Institute for Cancer Research (Continuous Update Project) conclude that there is "convincing evidence that consumption of processed meat cause colorectal cancer" (World Cancer Research Fund/American Institute for Cancer

\footnotetext{
${ }^{1}$ Corresponding author; National Food Institute, Kemitorvet, Bygning 221, 2800 Kgs. Lyngby, Denmark; E-mail address: hmej@food.dtu.dk
} 
Research, 2018). Other recent publications support the conclusion (Domingo \& Nadal, 2017; Vieira et al., 2017).

A former Danish report (Mejborn et al., 2016) concluded that in the epidemiological studies that has been given considerable weight in overall conclusions about associations between processed meat intake and colorectal cancer risk in humans, the term 'processed meat' covers a large, heterogeneous group of products that is manufactured and cooked in very different ways and can contain various chemical compounds that might have carcinogenic effects in highly variable concentrations. Often the individual publications from the epidemiological studies on associations between processed meat intake and colorectal cancer risk insufficiently describe what types of processed meat was included in the study. Though epidemiological studies cannot be used to establish a cause and effect relationship, information about the types of processed meat that is associated to cancer, is valuable information when attempting to identify the causative factors.

In our report we listed several processes and chemical compounds that could contrib ute or modulate the potential carcinogenic effect of processed meat: haem iron, nitrite/nitrate ( $\mathrm{N}$-nitroso compounds), antioxidants e.g. ascorbic acid and compounds produced from smoking or frying (PAH, HCA) (Mejborn et al. 2016). In 2016 World Cancer Research Fund showed that salt-preserved foods, which are mainly consumed in Asia, increase the risk of stomach cancer (World Cancer Research Fund/American Institute for Cancer Research, 2016). These compounds were also confirmed by Demeyer et al. (2015) and Jeyakumar et al. (2017) to be associated with the development of colorectal cancers in humans. The mechanisms linking these compounds to cancer risk are, however, not fully understood and needs further expl oration.

Since the carcinogenic compounds are present in varying amounts in different types of processed meat, we concluded that 'processed meat' is a diverse group of products, and it is not appropriate to regard it as one homogenous group in studies investigating the associations between intake and cancer risk (Mejborn et al., 2016). Even if the reported increase in cancer incidence relates to presently unknown factors, these factors are likely to vary between various types of processed meat. Hence, development of processed meat subgroups is a necessary step forward. Such subgroups should be used in future studies (both epidemiological and intervention studies) investigating associations between meat intake and cancer risk. The purpose of this paper is to suggest a division of processed meat on the Danish market in subgroups related to their carcinogenic potential. In other countries with different dietary habits (including food preparation), other subgroups may be relevant.

2. Materials and methods 


\subsection{Definitions}

We define "meat" as skeletal muscle and its associated tissue derived from mammalian, avian, reptilian, amphibian and aquatic species harvested for human consumption. "Edible offal" consists of organs and non-skeletal muscle tissue, and is al so considered meat (Seman et al., 2018). Edible offal can be an ingredient in Danish processed meat products, mainly luncheon meat.

Meat can be processed in several ways (Seman et al., 2018). Preserved meat is either smoked, dried, fermented (lactic acid bacteria (acidifying), moulds, yeast, Micrococcacea spp. (aroma generation)) or cured with different types of salt (sodium chloride, nitrite and nitrate salts) or a combination of these. Some preserved meat products can be eaten without further cooking, while others have to be heat treated (boiled, fried/deep fried, roasted, grilled/barbecued), before ingestion.

We define processed meat as meat that undergo a transformation and contain approved ingredients and may be subject to some form of preservation that may be combined with cooking, in other words: smoking, drying, curing, fermentation or roasting. We include industrially produced beef burgers with added salt, spices or other ingredients including food additives, since they are expected to be affected differently by processing than whole cuts. Also blood- and liver-containing products like liver paste, pâté and livercontaining sausages are included.

We define 'luncheon meat' as any of various sausages or molded meat loafs, usually sliced and served cold as in sandwiches or as garnishes for salads, but excluding salamis. 'Salami' is a fermented, dried, potentially smoked sausage that can be eaten without further preparation. We use the term 'sausages' for the type of sausages, including frankfurters, that are mostly further cooked and eaten as part of a hot meal in Denmark.

\subsection{Experimental setup}

We obtained information about processed meat products on the Danish market from GS1 Denmark (a barcode standard for a unique identification labelling system data exchange platform), producers' homepages or retailers' homepages. The products were chosen based on knowledge about Danes' dietary habits, and which processed meat products form significant contributions to Danes' meat intake (Pedersen et al., 2015).

Information obtained was: product name, producer, ingredient lists and nutrient declaration (salt/sodium). 
Presence of chemical compounds that could affect the potential carcinogenic effect of processed meat: haem iron, nitrite/nitrate, antioxidants (e.g. ascorbic acid) and processes (e.g. smoking or frying) contributing to formation of PAHs, HCAs and N-nitroso compounds was registered for each product based on the ingredient list. Since the ingredient list does not specify the actual quantity of most ingredients, the actual content of the compounds is not known.

Since we had no information about the haem iron content in the products, an approximation was made. On average, at least $50 \%$ of iron in meat is haem iron (variation $21-90 \%$ ). However, the total iron content depends to a large extent on animal species with the highest iron content in beef and lamb, medium-high content in pork and low content in poultry meat (Cross et al., 2012; Lombardi-Boccia et al., 2002). Some processed meat products may have a significant lower (haem) iron content (per $100 \mathrm{~g}$ ) than the meat, since other ingredients may be added (e.g. in the luncheon meat ' $\left.k \varnothing d p \varnothing \mid s e^{\prime}\right)$. We assigned the meat products the code ' $\mathrm{HIGH}$ ' when they contained veal, beef, lamb, blood or liver, 'MED' when they were made from pork only, and when they were made from pork and beef and the pork content was higher than the beef content, and 'LOW' when they were made from poultry (chicken or turkey) only.

Products containing nitrite (potassium nitrite E249, sodium nitrite E250) or nitrate (potassium nitrate E252, sodium nitrate E251) were coded as containing the actual compound.

Products containing antioxidants that have been shown to reduce formation of $\mathrm{N}$-nitrosamines from nitrite (ascorbic acid E300, ascorbate E303, sodium ascorbate E301, calcium ascorbate E302, erythorbic acid E315, sodium erythorbate E316) (EFSA, 2017a) were coded as containing the actual compound.

Information about whether products had been smoked was not always available. Thus, when information was missing we assumed that all processed pork filet ('hamburgerryg'), sausages, salamis and bacon were smoked, while dried ham, luncheon meat, liver paste/pate/molded meat, meatballs/loafs, 'medister' (Danish pork sausage), fried meat (e.g. roast beef) and beef burgers were not. Products containing 'liquid smoke' (aroma) were coded as smoked.

For the products that will rarely be fried by the consumers and products that are fried by the producers (e.g. fried meatballs) we used the code 'NO'; the remaining products were coded 'YES' for roasting.

Information about salt (sodium) content was obtained from nutrient declarations.

Overview of the possible outcomes of questions asked about content of the different potentially carcinogenic risk factors in processed meat products is shown in table 1. 
All products were divided in 12 products types according to general production and cooking methods for evaluation of potential cancer risk factors (table 2).

Based on information about content of potentially carcinogenic compounds, the product types were merged in processed meat subgroups based on presumed similar risk characteristics related to cancer.

\subsection{Statistical analyses}

Boxplot was used to illustrate the median and dispersion of salt content in different product types. The boxplot was prepared using the boxpl ot package in RStudio version 1.1.453 using the default settings of the boxplot package.

Independent samples medians test and independent t-test was used to test for the differences between salt content in subgroups of processed meat.

Chi-squared was used to test whether the product types differed regarding content of nitrite/nitrate, antioxidants, haem, smoke and preparation by the consumer was different among different types of processed meat.

The statistical analysis was carried out using SPSS, version 23 (IBM Corp., Armonk, NY, USA). 3. Results Information from 1051 processed meat products on the Danish market was obtained. We included information about beef burgers, since there are products on the market that are not just minced meat but containing other ingredients including food additives.

Content of potentially carcinogenic compounds differed significantly between product types. An overall description of differences is shown in annex 1 and given for each compound below.

\subsection{Haem iron}

In 74 products ( $7 \%$ of all), the haem iron content was assumed to be low, in 782 products ( $74 \%$ of all) assumed to be medium and in 195 products (19\% of all) assumed to be high based on type of meat in the product. Of the 195 products assumed to be high in haem iron, 63 products are luncheon meat, mainly liver containing pâté ( 27 products) and other products containing liver (10 products).

Overall, a significant higher proportion of products in FILET, LUNCH and ROAST types are characterised by having low haem iron content compared to SALA and SAUSA, and furthermore for ROAST compared to 
BACON, FILET, LUNCH and MED. For BACON, FILET, SALA and SAUSA significant more products had medium haem content compared to LUNCH, MEATB and ROAST. More products in LUNCH, MEATB and ROAST were characterised by having high haem content compared to BACON, FILET, SALA and SAUSA. For HAM significantly more products had high haem content compared to FILET and SAUSA, while in SALA there were more products with high haem iron than SAUSA.

ROAST is characterised by containing many products with low haem iron (fried, sliced chicken breast) and many products with high haem iron (fried, sliced beef).

\subsection{Nitrite and nitrate}

A large proportion of processed meat in Denmark contains nitrite as food additive ( 803 products, $76 \%$ of all products in this survey), while 11 products (1\%) contain only nitrate and 38 products (4\%) contain both nitrite and nitrate. All meat products labelled with the Danish logo for organic produce are made without added nitrite. We found 199 products (19\% of all products, both conventional and organic) without nitrite/nitrate, mostly beef burgers, fried meatballs, most of the liver paste and some luncheon meat. Potassium nitrate was added to 47 products ( $4 \%$ of all products), mostly salamis and dried ham, and in most products (36 products, $3 \%$ ) together with sodium nitrite. Sodium nitrate was added to two products in combination with sodium nitrite.

Overall, nitrite/nitrate were added to a significant lower proportion of LIVER, MED, MEATB and ROAST compared to other product types, while a higher proportion of BACON, FILET, SALA and SAUSA are characterised by a high proportion of products with added nitrite/nitrate compared to other product types.

The level of nitrite/nitrate in the products is not known, since listing the actual level of nitrate/nitrate in the ingredient lists is not mandatory.

\subsection{Antioxidants}

Of the 853 products containing nitrite or nitrate, 758 also contained the antioxidants ascorbic acid/ascorbate or erythorbic acid/erythorbate. Thus, 95 nitrite/nitrate containing products (11\%) do not contain these antioxidants (about $36 \%$ of the dried ham, $20 \%$ of products that had been fried by the producer (mainly fried, sliced chicken breast), 12 of the bacon and $11 \%$ of the luncheon meat).

HAM, LIVER, MEATB, MED and ROAST are characterised by a significant higher part of products without antioxidant, while for FILET, LUNCH, SALA and SAUSA a higher proportion of products with antioxidant 
compared to other product types. For BACON, LIVER and ROAST more products had antioxidants than MEATB.

\subsection{Smoke}

In total 658 products ( $63 \%$ of all) were assumed to be smoked or contained 'liquid smoke'. Information about smoke temperature was not available, neither was information related to method of smoking (where source of smoke was positioned compared to the meat).

The product types HAM and LUNCH were characterised by having more products not being s moked compared to SALA and SAUSA.

\subsection{Frying}

We identified 325 products (31\% of all) that we expect the consumers to prepare by roasting (frying pan, oven, grill), mainly bacon, beef burgers and sausages including frankfurters.

In the product types FILET, LUNCH and ROAST significant more products are not meant to be fried by the consumers compared to other product types. On the other hand, more BUR and SAUSA are meant to be fried by consumers.

\subsection{Salt}

Information about salt content was found for 827 products (79\% of all products). According to the nutrient declarations, salt varied from $0.1 \mathrm{~g} / 100 \mathrm{~g}$ to $8.1 \mathrm{~g} / 100 \mathrm{~g}$. Salt contents in different product types is shown in table 3 , and distribution of salt content in different product types is shown in figure 1. Figure 1 and table 3 show that there is difference in salt content between product types, HAM and SALA having a significant higher content. The variation in salt content is high $(C V>40)$ for the product types BACON, BUR, HAM, MEATB, ROAST and LUNCH. The salt content also varies considerably in SAUSA. An overview of potential carcinogenic factors in different types of products is shown in table 4.

In table 5 the suggested division into processed meat subgroups is shown.

\section{Discussion}

We identified 1051 processed meat products available on the Danish market. We cannot guarantee these products are representative for the total market. However, they represent a $n$ important part of the processed meat products eaten by the Danish population. Thus, we consider them valid as a basis for a division of processed meat in subgroups related to their carcinogenic potential. 
Recently, Seman et al. (Seman et al., 2018) published a paper on definitions of meat and classification of processing. However, no grouping of processed meat taking into account combinations of various processes is suggested. To our best knowledge, we are the first to suggest a uniform division of processed meat products in subgroups for investigation of associations between processed meat intake and cancer risk in humans. Therefore, a discussion of our subgroups compared to subgroups proposed by others is not applicable. Instead, we discuss the possible cancer risk factors in connection with the different types of processed meat products and the interactions between risk factors.

Our discussion primarily refers to Danish conditions, taking into consideration Danish dietary habits and processed meat products that are typical for the Danish market.

\subsection{Haem iron}

Haem iron was proposed as a carcinogen by Sawa et al. (1998). Haem iron is found only in red meat, poultry, seafood, and fish in varying amount. Thus, haem iron content in red meat products, including processed products, was suggested as an important carcinogenic parameter contributing to the associations found in epidemiologic studies (Bastide et al. 2016). An association between colorectal cancer risk and intake of iron, in particular haem iron, has been shown in several, but not all, epidemiologic studies (Ashmore et al. 2016). The epidemiological studies on the carcinogenic effects of haem iron are conflicting. Some studies indicate no association between high intake of haem and colon cancer (Brink et al., 2005; Egeberg et al., 2013; Larsson et al., 2005). Other studies, e.g. a well performed prospective cohort study by Bastide et al. (2016), indicate a strong association, and a high potency of haem iron. Possible mechanisms of action were discussed by Bastide et al. (2015), Demeyer et al. (2015) and Jeyakumar et al. (2017).

In this paper we have suggested a simplified division according to haem iron content. Veal has lower iron content than beef but is considered high-iron foods in our grouping. The only poultry products included were chicken and turkey products, mainly luncheon meat. Meat products based on duck, ostrich or goose meat have iron content equal to or higher than beef (Seman et al., 2018; USDA, 2018). However, such products constitute a minor market share in Denmark compared to products based on chicken or turkey, and the error introduced by eliminating such products is minor. In countries where such products are commonly consumed, appropriate grouping based on their haem content should be carried out. Likewise, processed meat produced from horse or rabbit is rarely found on the Danish market but in countries where such products are common, they should be grouped as high and medium iron products, respectively (Seman et al., 2018). 
The main processed meat products in a Danish diet with high haem iron content are beef burgers, luncheon meat (mainly liver containing products including pâtés), liver paste, and a few products made from pure beef (e.g. salted beef eye round,'saltk $\left.\varnothing d^{\prime}\right)$.

Controversy exists about the classification of pork as a red meat due to its low haem content compared to beef. Several studies have failed to show significant association between pork intake and cancer risk. However, a large part of the pig meat is being processed, and pork makes up a significant proportion of processed meat that has been clearly associated with increased cancer risk (Lippi et al., 2015).

In our report we reviewed the carcinogenic effect of haem iron and other iron species, including the proposed mechanisms. We concluded that it is very likely that haem iron is carcinog enic to humans but that the potency probably is low (Mejborn et al., 2016).

When evaluating the carcinogenic effect of (haem) iron, it must be taken into consideration that iron absorption is a regulated process (Huang, 2003). The possible carcinogenic effect of haem iron in colon is caused by local effects (Bastide et al., 2015). Therefore it can be assumed that few high doses of haem iron result in a higher cancer risk than several smaller doses. The effect of iron may also be affected by the presence of substances, e.g. fibres binding the iron, dietary antioxidants like vitamin E which scavenge reactive oxygen species, and substances like calcium and chlorophyll which may trap haem (Corpet, 2011). Therefore, eating less of the high-haem meat products at one meal, supplementing the meal with high-fibre foods like vegetables or whole-grain cereals and with fruits and vegetables containing antioxidants may reduce the carcinogenic potential of haem iron. However, in Denmark beef burgers and sausages are traditionally eaten with white fast-food bread, very little fruit, vegetables or whole-grain foods, while luncheon meat, liver paste and salamis normally are eaten with either whole-grain bread or white bread.

\subsection{Nitrite and nitrate}

Nitrite and nitrate has a long history of use in processed (cured) meat products (Pegg \& Honikel, 2014). Nitrite is added to inhibit growth of pathogenic bacteria, especially Clostridium botulinum that causes botulism. Besides, both nitrite and nitrate affects product colour and flavour (Sindelar \& Milkowski, 2012).

More than $80 \%$ of processed meat products in our survey contained nitrate or nitrite as food additive. Nitrate was only declared in products which al so contained nitrite except for 11 products ( 6 salami s and 5 dried ham products). A large proportion of the product types: organic bacon, black pudding, beef burgers, fried meatballs, liver paste and 'medister' did not contain nitrate/nitrite as food additive. Other preservatives were used in some of the nitrite/nitrate-free products. 
Safety concern for nitrite is primarily focused on its ability to react chemically with secondary amines to form $\mathrm{N}$-nitrosamines that are potentially carcinogenic.

Scientific evidence does not support an association between nitrate intake from foods and cancer risk (EFSA, 2017b; IARC, 2010).

The total evidence lead IARC to conclude that 'under conditions that result in endogenous nitrosation, ingested nitrate or nitrite is probably carcinogenic to humans (Group 2A)' (IARC, 2010). Others conclude that the scientific data on nitrite (or nitrate) being associated with cancer development is not supportive (Bryan et al. 2012; Sindelar \& Milkowski, 2012). A recent meta-analysis of the epidemiological studies indicated that nitrite increased the risk of gastric cancer (Song et al., 2015), a result that was partially (borderline) supported in a meta-analysis by Xie et al. (2016). EFSA (EFSA, 2017a) stated that "There was some evidence for a positive association between: dietary nitrite and gastric cancer or its subtypes gastric cardia adenocarcinoma and gastric non-cardia adenocarcinoma; and the combination of nitrite plus nitrate from processed meat and colorectal cancer or subtypes (colon or rectum) cancer". Moreover, there was 'evidence' for an association between preformed N-nitrosodimethylamine (NDMA) and increased risk of colorectal cancers.

Levels for maximum use of potassium nitrite/nitrate and sodium nitrite/nitrate as food additives in foods in the European Union are laid down in Regulation 1333/2008 (The European Parliament and the Concil of the European Union, 2008). The use level is product specific, since the technological need depends on factors like heat treatment applied, the $\mathrm{pH}$ and the water activity/salt concentration in the product (EFSA, 2010). However, the European Commission has approved national Danish provisions, which place more restrictive legislation than for the rest of the EU on adding potassium nitrite(E249) and sodium nitrite (E250) to certain meat products (The European Commission, 2015). National levels will al so apply to foods on the Danish market that were lawfully manufactured in other Member States.

EFSA (2017a) carried out an ad hoc analysis of nitrite in Danish meat products, showing that average nitrite levels were markedly lower compared to the nitrite levels in other member states. Around $50 \%$ lower for heat-treated and non-heat-treated processed meat and around $30 \%$ lower for traditional cured products. The lower nitrite levels in Danish meat products may be explained by the restricted nitrite use in Danish meat products. One study found that the content of volatile $\mathrm{N}$-nitrosamines known to be carcinogenic was generally low in Danish cured meat products (Herrmann et al., 2015a). It may be speculated that the result is due to good meat quality, restricted use of nitrite combined with a widespread use of ascorbate (see below), all factors that may inhibit the $\mathrm{N}$-nitrosamine formation (Herrmann et al., 2015c). 
Nitrite can be added indirectly to fermented foods (primarily salamis), when foods like celery, beetroot or "vegetable extracts" with high natural nitrate content are added as ingredients in combination with staphylococci or other Micrococcaceae species cultures that can convert nitrate to nitrite. In our survey we found 42 products ( $4 \%$ of all products) with celery, beetroot or dry vegetables/vegetableextract and starter culture. Six of the products - all organic- did not contain nitrite as food additive. Thus, it could be speculated if the vegetables were intentionally added as source of nitrite in these six products. We have no knowledge about the actual amount of nitrate added from the vegetable sources in these products, which complicates whether they should be grouped as containing nitrite. The formation of different $\mathrm{N}$-nitro compounds in meat products and their carcinogenic potential was discussed by Mejborn et al. (Mejborn et al., 2016), who concluded that it is unresolved whether $\mathrm{N}$-nitroso compounds ( $\mathrm{N}$-nitrosamines and similar compounds, e.g. N-nitrosamides) to some extent can explain the results from epidemiological studies on associations between intake of processed meat and cancer. What is certain, however, is that many Nnitroso compounds are genotoxic and potent carcinogens, and therefore there is a general rationale in minimizing these compounds in foods.

\subsection{Antioxidants}

$\mathrm{N}$-nitrosamine formation can be significantly reduced in the presence of the antioxidants ascorbic acid/ascorbate or erythorbic acid/erythorbate (Herrmann et al., 2015c; JECFA Joint FAO/WHO Expert Committee on Food Additives, 2003)

Herrmann et al. (Herrmann et al., 2015c) found that several factors, which can be controlled during the production, affected the levels of $\mathrm{N}$-nitrosamines in nitrite-preserved sausages, addition of erythorbic acid being the most effective. Increasing the added amount of erythorbic acid from $400 \mathrm{mg} / \mathrm{kg}$ to $1100 \mathrm{mg} / \mathrm{kg}$, increased the effectiveness of this approach. Addition of free iron (not haem) counteracted the beneficial effect of adding ascorbate or isoascorbate on $\mathrm{N}$-nitrosamine formation.

We identified how many of the products containing nitrite or nitrate that did not contain the antioxidants ascorbic acid/ascorbate or erythorbic acid/ erythorbate. We found that $11 \%$ of the nitrite/nitrate containing products was without the antioxidants.

\subsection{Smoke}

Meat products can be smoked for preservation and/or to enhance flav our. The smoke flavour can also be obtained by addition of 'liquid smoke' (water based condensates of wood smoke), which is regulated as an aroma in the European Union (The European Commission, 2013). 
Carcinogenic $\mathrm{N}$-nitrosamines can be formed in smoked meat products, where nitrous gasses can react with secondary amines (Lijinsky, 1999; Tricker \& Preussmann, 1991). Thus, the combination of curing and smoking may both contribute to the $\mathrm{N}$-nitrosamine formation.

Smoked meat products typically contain PAHs that are a large group of diverse substances generated by incomplete combustion or pyrolysis of organic matter (e.g. wood and coal). Thus meat that is grill-roasted /barbequed will be contaminated with PAHs. Several PAHs are shown to be genotoxic and carcinogenic in experimental animals (EFSA, 2008), and are therefore considered potentially carcinogenic for humans.

The content of PAHs in smoked meat depends on smoke temperature, the time exposed to smoke and on how the meat is exposed to smoke (direct or indirect smoke and/or use of filters). Also, the source of smoke (type and nature of wood) have an effect (Duedahl-Olesen et al. 2006).

We identified 658 smoked meat products, including 34 products with 'liquid smoke'. The smoked products were primarily from the product types: bacon, porkfilet, sausages including frankfurters and salamis.

Information about smoke temperature was only available for few products, and no information related to method of smoking (where source of smoke was positioned compared to the meat) was available. Smoking practice may be different in private homes and at small and medium size enterprises compared to large industry plants. 'Hot smoke' $\left(70-90^{\circ} \mathrm{C}\right)$ is rarely used for smoked meat in industry plants. In general, in industrial plants the temperature 'medium-hot' smoke $\left(40-60^{\circ} \mathrm{C}\right)$ is used for bacon, pork filet, sausages and smoked luncheon meat, while 'cold smoke' $\left(<30^{\circ} \mathrm{C}\right)$ is used for salamis (Tulip Food Company, personal information).

Bacon and the pork filet are smoked as whole cuts, so only the product surface is subject to the chemical substances formed during smoking. Since the PAHs only penetrate the outermost part of the meat, the amount of potentially carcinogenic compounds that consumers are exposed to from bacon and smoked pork filet is lower than from sausages including frankfurters, because the surface-to-weight ratio is lower in bacon and pork filet. PAHs in salamis were found to be lower than in sausages, probably due to the low smoke temperature normally used for salamis (Duedahl-Olesen et al., 2006).

So products being indirectly smoked at low-medium temperatures, preferably as whole cuts, are expected to have a limited PAH content.

In our study we assumed that all salamis were smoked, which is the normal production process in Denmark. However, in other European countries sausages are made without being smoked, especially 
salamis with surfaces colonised with moulds. Therefore, grouping salamis differently may be relevant in other countries.

\subsection{Frying}

In our previous report we demonstrated differences in associations between processed meat intake and colorectal cancer risk in American and European cohorts; the risk being higher in American cohorts (Mejborn et al., 2016), and the association being absent in Danish studies (Egeberg et al., 2013; Sørensen et al., 2008). Since dietary patterns and home - as well as industrial cooking methods differ widely between cultures, the results may be affected by both.

We distinguished industrially fried products from home-fried products, since we assume the industrial frying process used to manufacture processed meat products to result in less formation of potential carcinogenic compounds. Home frying, on the other hand, can potentiallybe performed in a way to significantly increase the content of HCAs (Aaslyng et al., 2013).

Frying, roasting or grilling produces HCAs on the meat surface (Murkovic, 2004; Turesky, 2007). Formation of HCAs take place at temperatures above $150^{\circ} \mathrm{C}$, and the highest amounts are produce $d$ by pan-frying, grilling, deep-frying and oven-roasting (Meurillon \& Engel, 2016). The HCA formation can be reduced by shorter cooking time and gentler heating (low temperature or turning the meat often).

When meat (raw and processed) is grilled directly above the heat source, melted fat and meat juice can drip down on the hot surface, thus forming $\mathrm{PAH}$-containing particles that may adhere to the meat surface. Such scenery is particularly important for fat meat products with a large, 'open' surface (e.g. minced meat like beef burgers). The effect was shown by Rose et al. (Rose et al., 2015). Rose et al. (2015) also showed that distance to the heat source affected the PAH content, which suggest that grilling directly above the heat source, including open flames, increase the risk of formation of carcinogenic compounds. Such methods are commonly used for home-frying.

Formation of $\mathrm{N}$-nitrosamines in nitrite cured meat are heat dependent (Herrmann et al., 2015b). Thus, keeping the frying temperature low may limit the formation, though frying temperatures can also causes evaporation and degradation of nitrosamines (De Mey et al., 2017; Herrmann et al., 2015b).

We did not take reheating into consideration, since any effect on formation of carcinogenic compounds will be covered by the effect of cooking methods discussed, primarily roasting on a frying pan, roasting in an oven or grilling. 
Preparing the processed meat products in a microwave is not discussed, because we consider the process comparable to cooking by boiling. We are not aware that boiling meat products will result in formation of new harmful substances. If the microwave's grill or frying program is used, the effects will be similar to effects of the same processes using a traditional oven.

\subsection{Salt}

High salt intake is mainly associated with increased risk of cardiovascular diseases, but also 'strong evidence' for an association between processed meat intake and risk of stomach (gastric) cancer is shown (World Cancer Research Fund/American Institute for Cancer Research, 2016). World Cancer Research Fund defines processed meat as meat that has been preserved by smoking, curing or salting, or by the addition of preservatives. Examples include ham, bacon, pastrami and salamis, as well as hot dogs and some sausages.

The salt content was not known for all products. The high-salt products $(\geq 4 \mathrm{~g} / 100 \mathrm{~g})$ that we identified were mainly the salamis and dried ham (approximately $50 \%$ of products with known salt content), but also a significant part of the beef burgers (25\%) were high in salt. Only $4 \%$ of bacon contained more than $4 \mathrm{~g} / 100$ $\mathrm{g}$, while $16 \%$ had more than $3 \mathrm{~g} / 100 \mathrm{~g}$. For sausages including frankfurters the corresponding figures were $8 \%$ and $16 \%$, respectively.

However, there was a large variation in salt content in some of the product types, which makes it possible for observant and circumspect consumers to choose low salt versions. Scientists should take this into consideration when discussing effects of high salt products on health.

\subsection{Strengths and weaknesses}

It is a strength that our survey includes a large and diverse number of processed meat products that are characteristic for the Danish market, and that we have collected information about presence of carcinogenic compounds from ingredient lists and nutrition declarations.

It is a weakness of the survey that we have no information about the quantitative content of haem iron, nitrite/nitrate and carcinogenic risk factors formed during smoking and cooking, and that we cannot be sure how the products are prepared by the consumers. However, it was outside the scope of this project to analyse more than one thousand products, and we consider the assumptions, we made instead, valid for most products.

It is also a weakness that no statistical method was used to make the subgrouping. We performed cluster analyses but found the method unsuitable because products were uncompromisinglyplaced in subgroups according to content of carcinogenic substances, e.g. bacon with nitrite in one group and bacon without nitrite in another group. Ideally, participants in epidemiological studies associating food intake to health 
risk should be asked about specific risk factors in their food. However, the average consumer will not be able to respond appropriately to such questions, which is why more general subgroups are useful .5. Conclusion

We suggest that in future studies investigating associations between consumption of processed meat and risk of cancer, processed meat should be treated as different subgroups due to potential differences in their carcinogenic risk factors. In Denmark the following subgroups are relevant: 1) sausages, 2) bacon, 3) beef burgers, 4) salamis and 5) other processed meat. These subgroups will be applicable in studies of processed meat-health associations among lay people without detailed knowledge of processed meats. Other subgroups may be more appropriate, depending on the hypothesis to be tested, or in other countries with different dietary habits and types of processed meat products on the market. In all cases it must be ensured that the subgroups reflect the dietary preferences of the stu dy population.

We suggest a distinction is made between meat products made from veal, beef, lamb, pork and poultry. Estimating the cancer risk from total intake of red meat and processed meat makes no sense, since the mechanisms involved may be very different.

\section{Abbreviations}

$\begin{array}{ll}\text { ADI } & \begin{array}{l}\text { Acceptable Daily Intake } \\ \text { BAC }\end{array} \\ \text { BUR } & \begin{array}{l}\text { Beef burger } \\ \text { BLOOD }\end{array} \\ & \text { Blood pudding } \\ \text { EFSA } & \text { The European Food Safety Authority } \\ \text { FILET } & \text { Pork filet } \\ \text { HAM } & \text { Dried ham } \\ \text { HCA } & \text { Heterocyclic Amines } \\ \text { IARC } & \text { International Agency for Research on Cancer } \\ \text { LIVER } & \text { Liverpaste } \\ \text { LUNCH } & \text { Luncheon meat } \\ \text { MEATB } & \text { Meatball } \\ \text { MED } & \text { 'Medister' (Danish pork sausage) } \\ \text { NDMA } & \text { NitrosoDiMethylAmine } \\ \text { PAH } & \text { Polycyclic Aromatic Hydrocarbons } \\ \text { ROAST } & \text { Fried whole meat } \\ \text { SALA } & \text { Salami } \\ \text { SAUSA } & \text { Sausage }\end{array}$

\section{Declaration of interest}


The work was supported by a grant from Danish Agriculture and Food Council (DAFC). DAFC had no influence on study design; on collection and interpretation of data; on the writing of the manuscript; or in the decision to submit the article for publication. 
References

Aaslyng, M. D., Duedahl-Olesen, L., Jensen, K., \& Meinert, L. (2013). Content of heterocyclic amines and polycyclic aromatic hydrocarbons in pork, beef and chicken barbecued at home by Danish consumers. Meat Science, 93, 85-91.

Ashmore, J. H., Rogers, C. J., Kelleher, S. L., Lesko, S. M., \& Hartman, T. J. (2016). Dietary Iron and Colorectal Cancer Risk: A Review of Human Population Studies. Critical Reviews in Food Science and Nutrition, 56, 1012-1020. https://doi.org/10.1080/10408398.2012.749208

Bastide, N. M., Chenni, F., Audebert, M., Santarelli, R. L., Taché, S., Naud, N., ... Pierre, F. H. F. (2015). A central role for heme iron in colon carcinogenesis associated with red meat intake. Cancer Research, 75(5), 870-879. https://doi.org/10.1158/0008-5472.CAN-14-2554

Bastide, N., Morois, S., Cadeau, C., Kangas, S., Serafini, M., Gusto, G., ... Boutron-Ruault, M.-C. (2016). Heme Iron Intake, Dietary Antioxidant Capacity, and Risk of Colorectal Adenomas in a Large Cohort Study of French Women. Cancer Epidemiology, Biomarkers \& Prevention, 25(4), 640-647. https://doi.org/10.1158/1055-9965.EPI-15-0724

Brink, M., Weijenberg, M., De Goeij, A., Roemen, G., Lentjes, M., De Brune, A., ... Van Den Brandt, P. (2005). Meat consumption and K-ras mutations in sporadic colon and rectal cancer in The Netherlands Cohort Study. British Journalof Cancer, 92(7), 1310-1320. https://doi.org/10.1038/sj.bjc.6602491

Bryan, N. S., Alexander, D. D., Coughlin, J. R., Milkowski, A. L., \& Boffetta, P. (2012). Ingested nitrate and nitrite and stomach cancer risk: An updated review. Food and Chemical Toxicology, 50(10), 36463665. https://doi.org/10.1016/j.fct.2012.07.062

Corpet, D. E. (2011). Red meat and colon cancer: Should we become vegetarians, or can we make meat safer? Meat Science, 89, 310-316.

Cross, A. J., Harnly, J. M., Ferrucci, L. M., Risch, A., Mayne, S. T., \& Sinha, R. (2012). Developing a heme iron database for meats according to meat type, cooking method and doneness level. Food and Nutrition Science, 3(7), 905-913. https://doi.org/10.4236/fns.2012.37120.Developing

De Mey, E., De Maere, H., Paelinck, H., \& Fraeye, I. (2017). Volatile N-nitrosamines in meat products: Potential precursors, influence of processing, and mitigation strategies. Critical Reviews in Food Science and Nutrition, 57, 2909-2923.

Demeyer, D., Mertens, B., De Smet, S., \& Ulens, M. (2015). Mechanisms Linking Colorectal Cancer to the Consumption of (Processed) Red Meat: A Review. Critical Reviews in Food Science and Nutrition, 8398(October), 2747-2766. https://doi.org/10.1080/10408398.2013.873886

Domingo, J. L., \& Nadal, M. (2017). Carcinogenicity of consumption of red meat and processed meat: A review of scientific news since the IARC decision. Food and Chemical Toxicology, 105, 256-261. https://doi.org/10.1016/j.fct.2017.04.028

Duedahl-Olesen, L., White, S., \& Binderup, M.-L. (2006). Polycyclic aromatic hydrocarbons (PAH) in Danish smoked fish and meat products. Polycyclic Aromatic Compounds, 26, 163-184.

EFSA. (2008). Scientific Opinion of the Panel on Contaminants in the Food Chain on a request from the European Commission on Polycyclic Aromatic Hydrocarbons in Food. EFSA Journal, 724(June), 1-114.

EFSA. (2010). EFSA Panel on Food Additives and Nutrient Sources added to Food (ANS); Statement on 
nitrites in meat products. EFSA Journal, 8(5), 1-12. https://doi.org/10.2903/j.efsa.2010.1538.

EFSA. (2017a). Re-evaluation of potassium nitrite (E 249) and sodium nitrite (E 250) as food additives. EFSA Journal, 15(6), 1-123. https://doi.org/10.2903/j.efsa.2017.4786

EFSA. (2017b). Re-evaluation of sodium nitrate (E 251) and potassium nitrate (E 252) as food additive. EFSA Journal, 15(6), 4787.

Egeberg, R., Olsen, A., Christensen, J., Halkjær, J., Jakobsen, M. U., Overvad, K., \& Tjønneland, A. (2013). Associations between red meat and risks for colon and rectal cancer depend on the type of red meat consumed. The Journal of Nutrition, 143, 464-472. https://doi.org/10.3945/jn.112.168799

Herrmann, S. S., Duedahl-Olesen, L., Christensen, T., Olesen, P. T., \& Granby, K. (2015). Dietary exposure to volatile and non-volatile $\mathrm{N}$-nitrosamines from processed meat products in Denmark. Food and Chemical Toxicology, 80, 137-143. https://doi.org/10.1016/j.fct.2015.03.008

Herrmann, S. S., Duedahl-Olesen, L., \& Granby, K. (2015). Occurrence of volatile and non-volatile Nnitrosamines in processed meat products and the role of heat treatment. Food Control, 48, 163-169. https://doi.org/10.1016/j.foodcont.2014.05.030

Herrmann, S. S., Granby, K., \& Duedahl-Olesen, L. (2015). Formation and mitigation of N-nitrosamines in nitrite preserved cooked sausages. Food Chemistry, 174, 516-526. https://doi.org/10.1016/j.foodchem.2014.11.101

Huang, X. (2003). Iron overload and its association with cancer risk in humans: Evidence for iron a s a carcinogenic metal. Mutation Research, 533(1-2), 153-171.

https://doi.org/10.1016/j.mrfmmm.2003.08.023

IARC. (2010). IARC Monographs on the Evaluation of Carcinogenic Risks to Humans, Vol 94, Ingested Nitrate and Nitrite, and Cyanobacterial Peptide Toxins. IARC Monographs on the Evaluation of Carcinogenic Risks to Humans / World Health Organization, International Agency for Research on Cancer, 94, v-vii, 1-412. https://doi.org/10.1002/food.19940380335

IARC. (2018). Red meat and processed meat. IARCMonographs on the Evaluation of Carcinogenic Risks to Humans, 114, 1-502.

JECFA Joint FAO/WHO Expert Committee on Food Additives. (2003). Nitarite (and potentialendogenous formation of N-nitroso compounds). WHO Food Additives Series No. 50. Retrieved from http://www.inchem.org/documents/jecfa/jecmono/v50je05.htm

Jeyakumar, A., Dissabandara, L., \& Gopalan, V. (2017). A critical overview on the biological and molecular features of red and processed meat in colorectal carcinogenesis. Journal of Gastroenterology, 52(4), 407-418. https://doi.org/10.1007/s00535-016-1294-x

Larsson, S. C., Rafter, J., Holmberg, L., Bergkvist, L., \& Wolk, A. (2005). Red meat consumption and risk of cancers of the proximal colon, distal colon and rectum: The Swedish Mammography Cohort. InternationalJournal of Cancer, 113, 829-834. https://doi.org/10.1002/ijc.20658

Lijinsky, W. (1999). N-Nitroso compounds in the diet. Mutation Research - Genetic Toxicology and EnvironmentalMutagenesis, 443(1-2), 129-138. https://doi.org/10.1016/S1383-5742(99)00015-0

Lippi, G., Mattiuzzi, C., \& Cervellin, G. (2015). Meat consumption and cancer risk: a critical review of published meta-analyses. Critical Reviews in Oncology/Hematology, 97, 1-14. 
https://doi.org/10.1016/j.critrevonc.2015.11.008

Lombardi-Boccia, G., Martinez-Dominguez, B., \& Aguzzi, A. (2002). Total Heme and Non-heme Iron in Raw and Cooked Meats. Food Chemistry and Toxicology, 67(5), 1738-1741.

Mejborn, H., Biltoft-Jensen, A., Hansen, M., Licht, T. R., Olesen, P. T., Ravn-Haren, G., \& Sørensen, I. K. (2016). Mechanisms behind cancer risks associated with consumption of red and processed meat . National Food Institute, Technical University of Denmark, Søborg.

Meurillon, M., \& Engel, E. (2016). Mitigation strategies to reduce the impact of heterocyclic aromatic amines in proteinaceous foods. Trends in Food Science and Technology, 50, 70-84. https://doi.org/10.1016/j.tifs.2016.01.007

Murkovic, M. (2004). Chemistry, formation and occurrence of genotoxic heterocyclic aromatic amines in fried products. European Journal of Lipid Science and Technology, 106(11), 777-785. https://doi.org/10.1002/ejlt.200400993

Pedersen, A. N., Christensen, T., Matthiessen, J., Knudsen, V. K., Sørensen, M. R., Biltoft-Jensen, A., ... Fagt, S. (2015). Danskernes kostvaner 2011-2013. Hovedresultater. DTU Fødevareinstituttet, Søborg.

Pegg, R. B., \& Honikel, K. O. (2014). Principles of Curing. Handbook of Fermented Meat and Poultry: Second Edition, 19-30. https://doi.org/10.1002/9781118522653.ch4

Rose, M., Holland, J., Dowding, A., Petch, S. R. G., White, S., Fernandes, A., \& Mortimer, D. (2015). Investigation into the formation of PAHs in foods prepared in the home to determine the effects of frying, grilling, barbecuing, toasting and roasting. Food and Chemical Toxicology, 78, 1-9.

Sawa, T., Akaike, T., Kida, K., Fukushima, Y., Takagi, K., \& Maeda, H. (1998). Lipid peroxyl radicals from oxidized oils and heme-iron: Implication of a high-fat diet in colon carcinogenesis. Cancer Epidemiology, Biomarkers \& Prevention, 7(11), 1007-1012.

Seman, D. L., Boler, D. D., Carr, C. C., Dikeman, M. E., Owens, C. M., Keeton, J. T., ... Powell, T. H. (2018). Meat Science Lexicon. Meat and Muscle Biology ${ }^{T M}$, 2, 1-15. https://doi.org/10.22175/mmb2017.12.0059

Sindelar, J. J., \& Milkowski, A. L. (2012). Human safety controversies surrounding nitrate and nitrite in the diet. Nitric Oxide - Biology and Chemistry, 26(4), 259-266. https://doi.org/10.1016/j.niox.2012.03.011

Sørensen, M., Autrup, H., Olsen, A., Tjønneland, A., Overvad, K., \& Raaschou-Nielsen, O. (2008). Prospective study of NAT1 and NAT2 polymorphisms, tobacco smoking and meat consumption and risk of colorectal cancer. Cancer Letters, 266, 186-193. https://doi.org/10.1016/j.canlet.2008.02.046

The European Commission. (2013). COMMISSION IMPLEMENTING REGULATION (EU) No 1321/2013 of 10 December 2013 establ ishing the Union list of authorised smoke flavouring primary products for use as such in or on foods and/or for the production of derived smoke flavourings. Official Journal of the European Union, 9(1321), 54-67.

The European Commission. (2015). COMMISSION DECISION (EU) 2015/826 of 22 May 2015 concerning national provisions notified by Denmark on the addition of nitrite to certain meat products. Official Journal of the European Union, (1129), 10-18.

The European Parliament and the Concil of the European Union. (2008). Regulation (EC) No 1333/2008 of the European Parliament and of the Council of 16 December 2998 on food additives. Official Journal of 
the European Union, (L354), 16-33.

Tricker, A. R., \& Preussmann, R. (1991). Carcinogenic N-nitrosamines in the diet: occurrence, formation, mechanisms and carcinogenic potential. Mutation Research/Genetic Toxicology, 259(3-4), 277-289. https://doi.org/10.1016/0165-1218(91)90123-4

Turesky, R. J. (2007). Formation and biochemistry of carcinogenic heterocyclic aromatic amines in cooked meats. Toxicology Letters, 168(3), 219-227. https://doi.org/10.1016/j.toxlet.2006.10.018

USDA. (2018). US food composition data. Retrieved from https://www. ars.usda.gov/northeastarea/beltsville-md-bhnrc/beltsville-human-nutrition-research-center/nutrient-data-laboratory/

Vieira, A., Abar, L., Chan, D. S. M., Vingeliene, S., Polemiti, E., Stevens, C., ... Norat, T. (2017). Food and beverages and colorectal cancer risk: a systematic review and met-analysis of cohort studies, an update of the evidence of the WCRF-AICR Continous Update Project. Annals of Oncology, $62 \mathrm{pp}$. https://doi.org/10.1093/annonc/mdx171

World Cancer Research Fund/American Institute for Cancer Research. (2016). Continuous Update Project Report: Diet, nutrition, physical activity and stomach cancer. World Cancer Research Fund International. Retrieved from http://www.wcrf.org/sites/default/files/Stomach-Cancer-2016Report.pdf

World Cancer Research Fund/American Institute for Cancer Research. (2018). Continuous Update Project Report: Meat , fish and dairy products and the risk of cancer. World Cancer Research Fund International, 1-78. Retrieved from https://www.wcrf.org/sites/default/files/Meat-Fish-and-Dairyproducts.pdf

Xie, L., Mo, M., Jia, H. X., Liang, F., Yuan, J., \& Zhu, J. (2016). Association between dietary nitrate and nitrite intake and sitespecific cancer risk: evidence from observational studies. Oncotarget, 7, 56915-56932. 
Table 1. Possible outcome of questions related to content of carcinogenic risk factors in processed meat

\begin{tabular}{|l|l|}
\hline Parameter & Outcome \\
\hline Haemoglobin content & $\begin{array}{l}\text { LOW - products made from poultry } \\
\text { MED - products made from pork, and from pork } \\
\text { and beef if pork is }>50 \% \text { of the total meat content } \\
\text { HIGH - products containing veal, beef, lamb, blood } \\
\text { or liver }\end{array}$ \\
\hline $\begin{array}{l}\text { Does the product contain nitrite or nitrate } \\
\text { potassium nitrite, sodium nitrite, potassium } \\
\text { nitrate, sodium nitrate)? }\end{array}$ & Actual compound \\
\hline $\begin{array}{l}\text { Does the product contain ascorbic acid, sodium } \\
\text { ascorbate,calcium ascorbate, ascorbate, erythorbic } \\
\text { acid, sodium erythorbate }\end{array}$ & Actual compound \\
\hline $\begin{array}{l}\text { Was the product smoked or does it contain smoke } \\
\text { aroma? }\end{array}$ & YES or NO \\
\hline $\begin{array}{l}\text { Will the food be roasted/fried/grilled by the } \\
\text { consumer before ingestion? }\end{array}$ & YES or NO \\
\hline Salt content & Declared value \\
\hline
\end{tabular}


Table 2. Division of processed meat products into product types according to general production and cooking methods for such products (product type names and abbreviations)

\begin{tabular}{|c|c|}
\hline Bacon (BACON) & +nitrite/nitrate, smoked, to be fried by the consumers ${ }^{1}$ \\
\hline Beef burgers (BUR) & may contain nitrite/nitrate, to be fried/grilled by the consumers \\
\hline Blood pudding (BLOOD) & +nitrite/nitrate, boiled, to be fried by consumers \\
\hline Dried ham (HAM) & +nitrite/nitrate, dried, some may be smoked ${ }^{2}$ \\
\hline Fried meatballs (MEATB) & No nitrite/nitrate, fried/roasted ${ }^{3}$ \\
\hline Fried whole meat (ROAST) & + nitrite/nitrate, fried/roasted ${ }^{4}$ \\
\hline Liver paste (LIVER) & No nitrite/nitrate, baked \\
\hline Luncheon meat (LUNCH) & + nitrite/nitrate, boiled ${ }^{5}$ \\
\hline 'Medister' (Danish pork sausage) (MED) & +nitrite/nitrate, to be fried by consumers \\
\hline Pork filet (FILET) & +nitrite/nitrate, smoked, to be boiled by the consumers ${ }^{6}$ \\
\hline Salamis (SALA) & +nitrite/nitrate, fermented, some may be smoked \\
\hline Sausages (SAUSA) & $\begin{array}{l}\text { + nitrite/nitrate, smoked, mostly to be fried or boiled by } \\
\text { consumers }{ }^{7}\end{array}$ \\
\hline
\end{tabular}

${ }^{1}$ Pancettaincluded;

${ }^{2}$ Prosciutto type, bresaola, pastrami;

${ }^{3}$ Mold-baked minced meat (meat loaf) included;

${ }^{4}$ Fried, often sliced meat;

${ }^{5}$ Bologna, Mortadella, boiled ham, chicken and turkey breast deli meat, rolled pork breast meat ('rullepølse'), pâté, meatballs, sausages with liver, head cheese;

${ }^{6}$ Smoked ham and smoked poultry breast included; smoked ham is not intended for boiling by consumers;

${ }^{7}$ Frankfurters, Vienna sausages, breakfast sausages, little smokies, bierwurst, smoked 'medister', smoked rolled pork breast-meat 
Table 3. Salt content $(\mathrm{g} / 100 \mathrm{~g})$ in different types of processed meat products

\begin{tabular}{|l|c|c|c|c|}
\hline Product type & $\mathbf{n}$ & Mean & S.dev. & CV, \% \\
\hline Bacon & 50 & $2.33^{\mathrm{b}}$ & 0.94 & 40.5 \\
\hline Beef burgers & 12 & $2.73^{\mathrm{b}}$ & 1.32 & 48.3 \\
\hline Blood pudding & 3 & $2.43^{\mathrm{b}}$ & 0.21 & 8.6 \\
\hline Dried ham & 21 & $3.59^{\mathrm{a}}$ & 1.49 & 41.3 \\
\hline Fried meatballs & 18 & $2.27^{\mathrm{b}}$ & 1.02 & 44.7 \\
\hline Fried whole meat & 31 & $2.38^{\mathrm{b}}$ & 1.27 & 53.4 \\
\hline Liver paste & 47 & $2.27^{\mathrm{b}}$ & 0.82 & 36.0 \\
\hline Luncheon meat & 166 & $2.61^{\mathrm{b}}$ & 1.09 & 41.5 \\
\hline 'Medister' (Danish pork & 22 & $2.34^{\mathrm{b}}$ & 0.77 & 32.9 \\
sausage) & 73 & $2.82^{\mathrm{b}}$ & 0.96 & 34.0 \\
\hline Pork filet & 153 & $3.76^{\mathrm{a}}$ & 1.17 & 31.1 \\
\hline Salamis & 231 & $2.44^{\mathrm{b}}$ & 0.89 & 36.5 \\
\hline $\begin{array}{l}\text { Sausages, including } \\
\text { frankfurters }\end{array}$ & & & & \\
\hline
\end{tabular}

Means in a column with different letters are significantly different $(p<0.05)$ 
Table 4. Potential carcinogenic factors in different types of processed meat products

\begin{tabular}{|c|c|c|c|c|c|c|c|c|c|c|c|c|c|}
\hline Factor & $\begin{array}{l}\text { Number of } \\
\text { products in } \\
\text { group }\end{array}$ & $\begin{array}{c}\text { BACON } \\
57\end{array}$ & $\begin{array}{c}\text { BLOOD } \\
3\end{array}$ & $\begin{array}{c}\text { BUR } \\
13\end{array}$ & $\begin{array}{c}\text { MEATB } \\
19\end{array}$ & $\begin{array}{c}\text { FILET } \\
89\end{array}$ & $\begin{array}{c}\text { LUNCH } \\
206\end{array}$ & $\begin{array}{c}\text { LIVER } \\
60\end{array}$ & $\begin{array}{c}\text { MED } \\
28\end{array}$ & $\begin{array}{c}\text { SAUSA } \\
292\end{array}$ & $\begin{array}{c}\text { SALA } \\
215\end{array}$ & $\begin{array}{c}\text { HAM } \\
28\end{array}$ & $\begin{array}{c}\text { ROAST } \\
41\end{array}$ \\
\hline Haem & $\begin{array}{l}195 \mathrm{HIGH}\left(19 \%^{\#}\right) \\
{[782 \mathrm{MED}} \\
\left.\left(74 \%^{\#}\right)\right]\end{array}$ & $\begin{array}{c}1 \\
{[52]}\end{array}$ & 3 & 13 & $\begin{array}{c}7 \\
{[10]}\end{array}$ & $\begin{array}{c}1 \\
{[78]}\end{array}$ & $\begin{array}{c}63 \\
{[112]}\end{array}$ & 60 & $\begin{array}{c}2 \\
{[25]}\end{array}$ & $\begin{array}{c}6 \\
{[279]}\end{array}$ & $\begin{array}{c}21 \\
{[190]}\end{array}$ & $\begin{array}{c}6 \\
{[22]}\end{array}$ & $\begin{array}{l}12 \\
{[14]}\end{array}$ \\
\hline +nitrite/nitrate & $853\left(81 \%^{\#}\right)$ & 51 & & & 2 & 83 & 179 & 18 & 7 & 269 & 197 & 23 & 23 \\
\hline $\begin{array}{l}\text { +nitrite/nitrate, } \\
\text {-antioxidant }\end{array}$ & $95\left(11 \%^{2}\right)$ & 7 & & & $\frac{L}{1}$ & 6 & 23 & & 2 & 15 & 23 & 10 & 8 \\
\hline Smoked & $658\left(63 \%^{\#}\right)$ & 55 & & & & 89 & 5 & 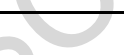 & & 291 & 214 & 4 & \\
\hline To be fried & $323\left(31 \%^{\#}\right)$ & 57 & 3 & 12 & & 1 & 2 & 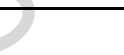 & 28 & 220 & & & 2 \\
\hline Salt > 3g/100 g & $264\left(32 \%^{*}\right)$ & 8 & & 4 & 4 & 25 & 44 & 7 & 4 & 37 & 111 & 13 & 7 \\
\hline Salt $\geq 4 \mathrm{~g} / 100 \mathrm{~g}$ & $156\left(19 \%^{*}\right)$ & 2 & & 3 & 2 & 11 & 20 & 3 & 1 & 19 & 84 & 10 & 1 \\
\hline
\end{tabular}

\#\% of all products (1051);

* \% of products with known salt content (827);

\& \% of nitrite/nitrate containing products (853) 
Table 5. Division of processed meat products into subgroups applicable for investigation of associations between processed meat intake and cancer risk

\begin{tabular}{|c|c|}
\hline Subgroup & Explanation \\
\hline Sausages & $\begin{array}{l}\text { The presence of nitrite increases the risk of } \\
\text { formation of N-nitrosamines. Sausages are smoked } \\
\text { at a medium-high temperature, which increases the } \\
\text { risk of N-nitrosamine formation. They have a } \\
\text { relatively high surface-to-weight ratio, which } \\
\text { increases the content of harmful compounds } \\
\text { formed during smoking. Sausages are mainly eaten } \\
\text { as fried or grilled, which increase the PAH and HCA } \\
\text { content. }\end{array}$ \\
\hline Bacon & $\begin{array}{l}\text { Risk of } \mathrm{N} \text {-nitrosamine formation from nitrite. The } \\
\text { combination of nitrite and frying increases the } \mathrm{N} \text { - } \\
\text { nitrosamine content. The risk from smoking is } \\
\text { considered less problematic due to the low surface- } \\
\text { to-weight ratio. Bacon is fried (normally pan-fried) } \\
\text { before ingestion which increase the risk of HCA } \\
\text { formation }\end{array}$ \\
\hline Beef burgers (minced meat) & $\begin{array}{l}\text { Beef burgers have a high haem content that can } \\
\text { potentially be harmful, since beef burgers are often } \\
\text { eaten in high amounts in meals without the } \\
\text { protecting effect from other foods with high fibres } \\
\text { or antioxidants. Beef burgers are eaten as fried - } \\
\text { often grilled, which increase the risk of PAH and } \\
\text { HCA formation. They have a large surface-to weight } \\
\text { which increase the PAH content when grilled or } \\
\text { intensely fried. Industrially produced beef burgers } \\
\text { often have a high salt content. }\end{array}$ \\
\hline Salamis & $\begin{array}{l}\text { The presence of nitrite increases the risk of } \\
\text { formation of } \mathrm{N} \text {-nitrosamines and salamis often do } \\
\text { not contain antioxidants that reduce the } \mathrm{N} \text { - } \\
\text { nitrosamine formation. Even though the low pH in } \\
\text { the fermented salamis could increase } \mathrm{N} \text { - } \\
\text { nitrosamine formation, the risk from smoking is } \\
\text { considered less problematic due to the low smoking } \\
\text { temperature used on salamis. Not all salamis are } \\
\text { smoked. Salamis may have a high salt content. }\end{array}$ \\
\hline Other processed meat products & $\begin{array}{l}\text { This subgroup is somewhat heterogeneous but } \\
\text { overall the products contain a lower number of } \\
\text { cancer risk factors than other subgroups. The } \\
\text { subgroup includes, but is not limited to, smoked } \\
\text { nitrite-containing pork filet with a low surface-to- } \\
\text { weight ratio, boiled ham and dried ham with nitrite, } \\
\text { liver paste with high haem content, pâté containing } \\
\text { liver and nitrite, fried or boiled sliced meat with } \\
\text { nitrite. }\end{array}$ \\
\hline
\end{tabular}




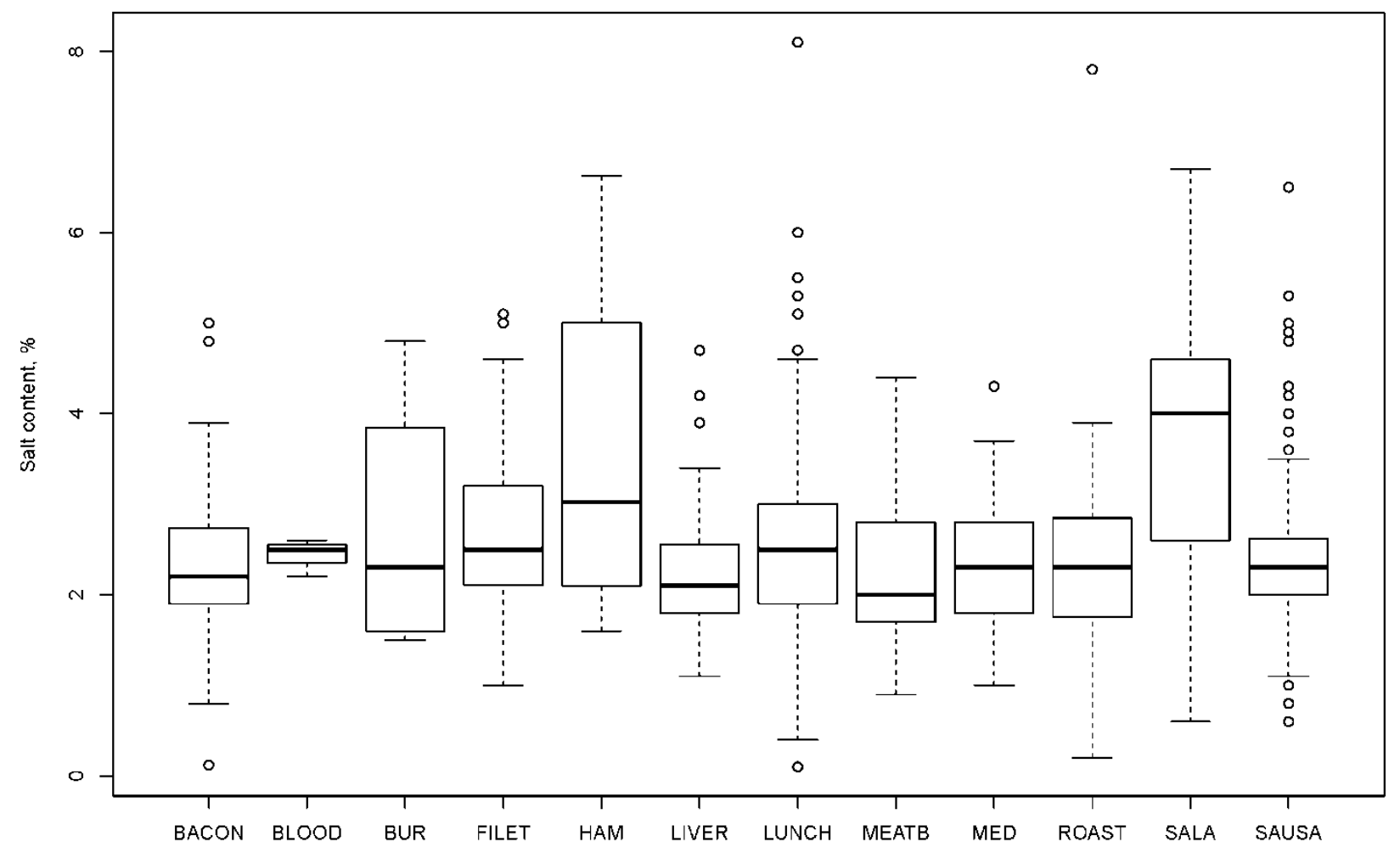

Figure 1.Distribution of salt $(\mathrm{g} / 100 \mathrm{~g})$ in different types of meat product on the Danish market. The height of the box spans the second and third quartile. The horizontal line in the box indicates the median. The length of the upward whisker is either to the highest observed value, or to the third quartile plus 1.5 times the height of the box, whichever is smaller. The length of the downward whisker is either to the smallest observed value, or to the first quartile minus 1.5 times the height of the box, whichever is greater. Values falling outside the range of the whiskers are regarded outliers and are plotted as circles. Legends: BACONbacon; BLOOD - blood pudding; BUR - beef burgers; FILEt - PORK FILET; ham - dried ham; LIVER - liver paste; LUNCH - luncheon meat; MEATB - fried meatballs; MED - 'medister'; ROAST-fried whole meat; SALA - salamis; SAUSA - sausages including frankfurters. 
Annex 1. Statistical significant differences in content and processing of different types of meat products

Comparisons of column proportions ${ }^{b}$

\begin{tabular}{|c|c|c|c|c|c|c|c|c|c|c|c|c|c|}
\hline Parameter & & $\begin{array}{c}\text { BACON } \\
\text { (A) }\end{array}$ & $\begin{array}{l}\text { FILET } \\
\text { (B) }\end{array}$ & $\begin{array}{l}\text { SALA } \\
\text { (C) }\end{array}$ & $\begin{array}{l}\text { SAUSA } \\
\text { (D) }\end{array}$ & $\begin{array}{l}\text { BUR } \\
\text { (E) }\end{array}$ & $\begin{array}{c}\text { BLOOD } \\
\text { (F) }\end{array}$ & $\begin{array}{l}\text { HAM } \\
\text { (G) }\end{array}$ & $\begin{array}{c}\text { MEATB } \\
\text { (H) }\end{array}$ & $\begin{array}{l}\text { ROAST } \\
\text { (I) }\end{array}$ & $\begin{array}{l}\text { LIVER } \\
\text { (J) }\end{array}$ & $\begin{array}{l}\text { LUNCH } \\
\text { (K) }\end{array}$ & $\begin{array}{l}\text { MED } \\
\text { (L) }\end{array}$ \\
\hline \multirow[t]{3}{*}{ Haem iron } & Low & & $\mathrm{CD}$ & & & $a$ & $\mathrm{a}$ & $\mathrm{a}$ & & $\mathrm{ABCDKL}$ & $a$ & CD & \\
\hline & Medium & HIK & HIK & HIK & GHIK & $\mathrm{a}$ & $\mathrm{a}$ & $T$ & ) & $\nabla$ & $\mathrm{a}$ & & $\mathrm{IK}$ \\
\hline & High & & & $\mathrm{D}$ & & $\mathrm{a}$ & $\mathrm{a}$ & $\mathrm{BD}$ & $\overline{A B C D}$ & $\overline{A B C D}$ & $\mathrm{a}$ & $\overline{A B C D}$ & \\
\hline \multirow[t]{2}{*}{ Nitrite/nitrate } & No nitrite/nitrate & & & & & $\mathrm{a}$ & $\mathrm{a}$ & 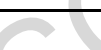 & ABCDGIK & ABCDK & ABCDGK & & $\overline{A B C D G K}$ \\
\hline & $\begin{array}{l}\text { Nitrite/nitrate/both } \\
\text { added }\end{array}$ & HIJL & HIJL & HIJL & HIJL & a & & HJL & & $\mathrm{H}$ & HIJL & & \\
\hline \multirow[t]{2}{*}{ Antioxidant } & Not added & & & & & $\mathrm{a}$ & a & BCDK & $\overline{A B C D I J K}$ & $\mathrm{BCD}$ & BCDK & & $\overline{B C D K}$ \\
\hline & Added & $\mathrm{H}$ & GHIJL & GHIJL & GHIJL & $a$ & $a$ & & & $\mathrm{H}$ & $\mathrm{H}$ & GHJL & \\
\hline \multirow[t]{2}{*}{ Smoked } & Not smoked & $a$ & $\mathrm{a}$ & & & $\mathrm{a}$ & $a$ & $\overline{C D}$ & $\mathrm{a}$ & $a$ & $a$ & $C D$ & \\
\hline & Smoked & $a$ & $a$ & GK & & $a$ & $a$ & & $\mathrm{a}$ & $a$ & $\mathrm{a}$ & & \\
\hline \multirow[t]{2}{*}{ Fried } & $\begin{array}{l}\text { No frying by } \\
\text { consumer }\end{array}$ & a & $\mathrm{DE}$ & & & & a & a & a & $\mathrm{DE}$ & a & $\mathrm{DE}$ & $\mathrm{a}$ \\
\hline & Frying by consumer & $a$ & & $\mathrm{a}$ & BIK & BIK & $a$ & $\mathrm{a}$ & $\mathrm{a}$ & & $\mathrm{a}$ & & $a$ \\
\hline
\end{tabular}

Results are based on two-sided tests with significance level 0.05 . For each significant pair, the key of the category with the smaller column proporti on appears under the category with the larger column proportion;

${ }^{a}$ This category is not used in comparison because its column proportion is equal to zero or one;

${ }^{\mathrm{b}}$ Tests are adjusted for all pairwise comparisons within a row of each innermost subtable using the Bonferroni correction 